\title{
Prognostic impact of discrepant Ki67 and mitotic index on hormone receptor-positive, HER2-negative breast carcinoma
}

\author{
L Rossi $^{1}$, E Laas ${ }^{2}$, P Mallon ${ }^{3}$, A Vincent-Salomon ${ }^{4}$, J-M Guinebretiere ${ }^{4}$, F Lerebours ${ }^{5}$, R Rouzier ${ }^{1,6}$, J-Y Pierga $^{5}$ \\ and F Reyal ${ }^{\star 1,7,8}$
}

${ }^{1}$ Département de chirurgie, Institut Curie, 75005 Paris, France; ${ }^{2}$ Service de Gynécologie-Obstétrique, Hôpital Tenon, 75020 Paris, France; ${ }^{3}$ Craigavon Area Hospital Breast Unit BT63 50Q, Portadown, Northern Ireland; ${ }^{4}$ Département de biologie des tumeurs, Institut Curie, 75005 Paris, France; ${ }^{5}$ Département d'oncologie médicale, Institut Curie, 75005 Paris, France; ${ }^{6}$ Equipe d'Accueil 7285, 'Risk and Safety in Clinical Medicine for women and Perinatal Health', University Versailles-Saint-Quentin, 78180 Montigny-leBretonneux, France; ${ }^{7}$ Département de recherche translationnelle, Equipe résidu tumoral et réponse au traitement, Institut Curie, 75005 Paris, France and ${ }^{8}$ INSERM U932 Immunity and Cancer, Institut Curie, 75005 Paris, France

Background: Inconsistencies between mitotic index (MI) and Ki67 measures have been identified in many breast tumour samples. The aim of this study was to describe the prognosis of hormone receptor-positive (HR+) HER2 - tumours having discrepant MI and Ki67.

Methods: We included a cohort of breast cancer patients initially treated by surgery between 2001 and 2005 in the Institut Curie. Breast cancer-specific survival (BCSS) and disease-free survival (DFS) were analysed according to three proliferation groups: high $\mathrm{Ml} /$ high Ki67 ( $\mathrm{Ml}=3$, Ki67 > 20\%), low Ml/low Ki67 $(\mathrm{Ml}<3, \mathrm{Ki67} \leqslant 20 \%)$ and discrepant (high Ml/low Ki67 or low Ml/high Ki67).

Results: Among the 1430 patients, $19.6 \%$ had discrepant Ki67 and Ml, 11.6\% had high markers and $68.8 \%$ had low markers. The 5-year BCSS was $95.8 \%, 95 \% \mathrm{Cl}(0.93-0.98)$ in the discrepant group, $99.3 \%, 95 \% \mathrm{Cl}(0.993-0.999)$ in the low-proliferation group and $91.8 \%, 95 \% \mathrm{Cl}(0.88-0.96)$ in the high-proliferation group. In multivariate analysis, the survival of the discrepant group was lower than that of the low-proliferation group: BCSS hazard ratio $(H R)=3.01(1.32-6.84 ; P=0.008)$ and DFS HR $=2.07,95 \% \mathrm{Cl}$ (1.31-3.26; $P=0.002)$. Among grade 2 tumours in multivariate analysis, DFS of the discrepant group was lower than that of the low $\mathrm{MI} /$ low Ki67 group: $\mathrm{HR}=1.98,95 \% \mathrm{Cl}(1.14-3.46), P=0.02$. Regarding $\mathrm{BCSS}$, the obtained results were similar.

Conclusion: The prognosis of patients with discrepant MI and Ki67 appears intermediate between that of low MI/low Ki67 and high MI/high Ki67 groups. These markers should be jointly analysed to clarify prognosis.

The assessment of tumour proliferation is a central determinant of adjuvant treatment decision in breast carcinoma. Ki67 and mitotic index (MI) are indicators of the tumour proliferation rate; however, inconsistencies between them have been identified in many tumour samples. This may interfere with adjuvant therapeutic decisions especially in patients with hormone receptorpositive $(\mathrm{HR}+)$, HER2-negative (HER2 - ) tumours.

The mitotic count is usually performed on 10 consecutive fields in the most cellular region at the periphery of the tumour in order to obtain a standardised MI (Standardized Mitotic Index, number of mitotic figures per $\mathrm{mm}^{2}$; Jalava et al, 2006). Although MI is regarded as a good indicator of cell proliferation, there are limitations to its accuracy as mitosis rates vary particularly in aneuploid tumours (Sennerstam and Auer, 1990). Furthermore, the cell cycle itself fluctuates in duration and stops may occur in mitotic metaphase. All these factors may alter the proportion of visible mitosis within the same tumour at different times. A rapid tumour-doubling time may be related to short cell cycles

*Correspondence: Dr F Reyal; E-mail: fabien.reyal@curie.fr

Revised 12 June 2015; accepted 4 June 2015; published online 17 September 2015

(c) 2015 Cancer Research UK. All rights reserved 0007-0920/15 
or to a significant fraction of growing cells. Thus, the correlation between the number of mitosis and the proliferation rate is not strictly linear (Beresford et al, 2006).

The MI is a major prognostic factor in that patients with high MI have an increased risk of death (Stuart-Harris et al, 2008) and recurrence regardless of tumour size (Baak et al, 2008) and lymph node status (Baak et al, 2005). There is also evidence to suggest that MI predicts response to adjuvant (Andre et al, 2005; Janssen et al, 2006) and neoadjuvant (Vincent-Salomon et al, 2004; Penault-Llorca et al, 2008) chemotherapy.

The nuclear Ki67 antigen is expressed in the cell cycle phases G1, S, G2 and M, but not in G0. The level of expression of the Ki67 protein varies during the cell cycle. Rates are low in G1 and early S phase and increase to a maximum at the time of mitosis. A rapid decrease in Ki67 expression occurs in anaphase and telophase (Lopez et al, 1991). To identify cells expressing the Ki67 protein, immunohistochemistry is performed using a mouse monoclonal antibody. MIB-1 antibody has been validated more frequently (Harris et al, 2007). Immunohistochemistry can be used on tissue sections embedded in paraffin. The half-life of Ki67 is estimated to be $\sim 60-90 \mathrm{~min}$, and the duration of a cell cycle is $\sim 24 \mathrm{~h}$. Normal breast tissue and oestrogen receptor positive $(\mathrm{ER}+)$ tumour cells express $\mathrm{Ki} 67$ at low levels $(<3 \%)$, whereas ER - tumours exhibit higher expression (Clarke et al, 1997). The percentage of tumour cells expressing Ki67 reflects the percentage of cells in the mitotic cycle within the tumour. Several studies support the prognostic value of Ki67 (Reyal et al, 2013). In the meta-analysis by De Azambuja et al (2007), patients with high Ki67 had worse diseasefree survival (DFS; hazard ratio $(\mathrm{HR})=1.93(1.74-2.14), P<0.001)$ and overall survival (OS; $H R=1.95(1.70-2.24), P<0.001)$. Ki67 was also an independent prognosis factor in node-negative and node-positive patients. Stuart-Harris et al (2008) found similar results in their meta-analysis. The ability of Ki67 to predict the response to chemotherapy is controversial (Dowsett et al, 2011). Viale et al in 2008, in their analysis of 1521 patients without lymph node involvement, did not show any predictive value of Ki67 in response to adjuvant chemotherapy.

Mitotic index and Ki67 both evaluate the proliferative potential of tumours; however, we have observed in some patients' discordance between the two markers. The aim of this study was to determine the characteristics and the prognosis of HR + HER2 - breast cancers having high Ki67/low MI or low Ki67/high MI.

\section{MATERIALS AND METHODS}

Patients. This study included a cohort of patients with a first invasive breast cancer treated in the Institut Curie between January 2001 and December 2005. The inclusion criteria were HR + (ER + and/or progesterone receptor-positive $(\mathrm{PR}+))$ HER2 - tumours with a pathological size ranging from T1 to T3 (TNM classification) with or without lymph node involvement, no distant metastasis at diagnosis and surgery as first treatment. Patients with missing values for Ki67 or MI were excluded because they were not classifiable in a 'proliferation group' required for the analysis.

Data measurement. All data were collected prospectively.

Pathological characteristics. The resected specimens were fixed in AFA (alcohol-formalin-acetic acid solution), and then embedded in paraffin and cut into sections of $3-5-\mu \mathrm{m}$ thickness. The slides were stained with haematoxylin, eosin and saffron. Tumour size was macroscopically determined on the fresh resected specimen. Pathological grade was assessed according to Elston \& Ellis.

Mitotic index. The MI was assessed in the peripheral most cellular region of the tumour slides. The criteria of Van Diest et al (1992) were used to define mitotic figures. The MI was the sum of the number of mitosis counted on 10 consecutive high-power fields (each area of $0.307 \mathrm{~mm}^{2}$ ) using an optical microscope (objective $\times 40$ ). According to Elston \& Ellis' grade (Elston and Ellis, 1991), the thresholds used were as follows: 1 point when $<9$ mitosis were counted, 2 points when $10-19$ mitosis were counted and 3 points if mitosis were $\geqslant 20$ per 10 fields. We considered that MI was low if the score was equal to 1 or 2 , and high if the score was equal to 3 . According to our microscope, this sets a cutoff to 19 mitosis $\mathrm{mm}^{-2}$.

\section{Immunohistochemical characteristics}

Ki67 rate. Tissue sections were incubated with the anti-Ki67 monoclonal antibody (Clone MIB-1 M7240, Dako, Glostrup, Denmark). The revelation of the staining was performed using a peroxidase mouse IgG kit and diaminobenzidine as chromogen. The validity of each procedure was verified with the staining of internal controls (lymphocytes, mitosis). The semiquantitative gross assessment was performed by determining at $\times 200$ magnification the percentage of positive neoplastic nuclei within the area of highest positivity. All nuclei with homogeneous staining even with a light staining or only a nucleolar staining were interpreted as positive. A cutoff of $>20 \%$ was used to define tumours with a high KI67 rate.

$E R$ and $P R$ status. After rehydration and antigenic retrieval in citrate buffer $(10 \mathrm{~mm}, \mathrm{pH} 6.1)$, the tissue sections were stained for ER (clone 6F11, Novocastra, 1 out of 200) and PR (clone 1A6, Novocastra, 1 out of 200). Revelation of staining was performed using the Vectastain Elite ABC peroxidase mouse IgG kit (Vector, Burlingame, CA, USA) and diaminobenzidine (Dako A/S) as chromogen. Positive and negative controls were included in each slide run. Cases were considered positive for ER and PR according to the standardized guidelines using a cutoff of $\geqslant 10 \%$ stained tumour nuclei (Balaton et al, 1996).

HER2 status. After rehydration and antigenic retrieval in citrate buffer $(10 \mathrm{~mm}, \mathrm{pH} 6.1)$, the tissue sections were stained for HER2 (clone CB11, Novocastra, 1 out of 1000). Revelation of staining was performed using the Vectastain Elite ABC peroxidase mouse IgG kit (Vector) and diaminobenzidine (Dako A/S) as chromogen. Positive and negative controls were included in each slide run. The overexpression of HER2 was determined according to the GEFPICS guidelines with FISH performed in all cases of HER2 $2+$ result (Penault-Llorca et al, 2010).

Statistical analysis. Patients were classified into three 'proliferation groups': high MI/high Ki67 ( $\mathrm{MI}=3$ and Ki67 > 20\%), low MI/ low Ki67 (MI = 1 or 2 and Ki67 $\leqslant 20 \%)$ and discrepant (high MI/ low Ki67 or low MI/high Ki67). Data were analysed using $\chi^{2}$-test or Fisher exact test for qualitative variables and by Student's $t$-test for quantitative variables. Breast cancer-specific survival was described using the time from diagnosis to the time to death of breast cancer. Disease-free survival was described using the time from diagnosis to the time of a recurrence (local recurrence or lymph node recurrence or distant metastasis). Survival analyses were performed using the Kaplan-Meier estimate of the survival function. Comparison between survival curves was performed using the log-rank test. Hazard ratios were estimated using the Cox proportional hazard model. Only variables with a $P$-value $<0.1$ in univariate analyses were included in a multivariate ascending stepwise procedure using the Cox model. There was $<5 \%$ missing data for all the variables. All statistical tests were reported with two-tailed $P$-values and 95\% CIs at an alpha level of 0.05 or lower. All statistical analyses were performed using the R software (http:// cran.r-project.org, The R Foundation for Statistical Computing, Vienna, Austria, version 0.98.978, 2009-2013 RStudio Inc.) with the rms and survival packages. 
Ethical consideration. The registration of patients of the Institut Curie in this cohort received a favourable agreement from the French National Committee on Computers and Liberties (CNIL, Commission nationale de l'informatique et des libertes). Patients gave informed written consent before being registered in the cohort. The study was approved by the breast cancer study group and the comity of clinical research study of the Institut Curie.

\section{RESULTS}

Patients. Among the 1487 patients with a HR + HER2 - invasive breast cancer treated by surgery first, 52 patients were excluded because they had a missing value for Ki67 or MI and five because they had missing data on the cause of death. Consequently, 1430 women treated in the Institut Curie between 2001 and 2005 were analysed (Table 1).

Proliferation groups. Proliferation groups were distributed as follows: 984 patients (68.8\%) had low MI/low Ki67, 166 (11.6\%) high MI/high Ki67 and 280 (19.6\%) discrepant markers (227 (15.9\%) low MI/high Ki67 and 53 (3.7\%) high MI/low Ki67; Table 1). There was no statistical difference between the high MI/ low Ki67 and the low MI/high Ki67 groups, regarding patient characteristics, tumour characteristics or administered treatments.

The median Ki67 in the high MI/low Ki67 group was 15\%. This median of $15 \%$ was significantly higher than that of the low MI/low Ki67 group (median $=8 \%$ ). In the low MI/high Ki67 subgroup, the median Ki67 was 30\%. This median of $30 \%$ was significantly lower than that of the high MI/high Ki67 group (median $=45.8 \%$ ). Mitotic index of this subgroup low MI/high Ki67 was measured equal to 1 in $46 \%$ of cases (104 patients) and to 2 in $54.2 \%$ of cases (123 patients).
In the high MI group ( $\mathrm{MI}=3$ ), the first quartile value of Ki67 was $21.5 \%$. The low Ki67 values of this group were not only values nearer to the threshold of $20 \%$ (Figure 1). When MI was low (equal to 1 or 2 ), around one quarter of the Ki67 values were $\geqslant 20 \%$ and were not only near the threshold of $20 \%$ but also could reach really high values.

Tumour sizes greater than $20 \mathrm{~mm}$ in the discrepant group were more frequent (31.5\%) than in the low MI/low Ki67 group (19.5\%) and less frequent than in the high MI/high Ki67 one (43.4\%), $P<0.001$ (Table 1). Moreover, axillary lymph nodes in the discrepant group were more often metastatic (43.1\%) than in the low MI/low Ki67 (28.9\%) group and less often than in the high MI/ high Ki67 one (47\%), $P<0.001$. The discrepant group had grade 3 tumours in higher proportion (20.0\%) than the low MI/low Ki67 group (1\%) and in lower proportion than the high MI/high Ki67 group (68.1\%), $P<0.001$ (Table 1 ).

BCSS and DFS. The median follow-up was 73 months. The BCSS rate at 5 years was $99.3 \%, 95 \%$ CI (0.993-0.999) in the low MI/low Ki67 group, 95.8\%, 95\% CI (0.93-0.98) in the discrepant group and $91.8 \%, 95 \%$ CI $(0.88-0.96)$ in the high MI/high Ki67 group. In the univariate analysis, the discrepant group had an intermediate BCSS (Figure 2A) and DFS (Figure 2B) compared with the two other groups. The relative risks of death due to breast cancer of the discrepant and the high MI/high Ki67 groups were higher than those of the low MI/low Ki67 group, HR $=4.35$, 95\% CI (2.069.21; $P=0.0001)$ and $\mathrm{HR}=9.77,95 \% \mathrm{CI}(4.80-19.89 ; P<0.0001)$, respectively (Figure $2 \mathrm{~A}$ ). Similarly, the relative risks of recurrence were higher in the discrepant and in the high MI/high Ki67 groups compared with the low MI/low Ki67 group, $\mathrm{HR}=2.49,95 \% \mathrm{CI}$ $(1.64-3.76 ; \quad P<0.0001)$ and $\mathrm{HR}=4.97,95 \%$ CI $\quad(3.32-7.43$; $P<0.0001$ ), respectively (Figure $2 \mathrm{~B}$ ).

Table 1. Characteristics of the HR + HER2 - population according to proliferation groups

\begin{tabular}{|c|c|c|c|c|c|c|c|c|}
\hline \multirow[b]{2}{*}{ Variable/category } & \multicolumn{2}{|c|}{ Low MI/low Ki67 } & \multicolumn{2}{|c|}{ Discrepant } & \multicolumn{2}{|c|}{ High MI/high Ki67 } & \multirow[b]{2}{*}{$P$-value } & \multirow[b]{2}{*}{ All; $N(\%)$} \\
\hline & $N$ & $\%$ & $N$ & $\%$ & $N$ & $\%$ & & \\
\hline All & 984 & 68.8 & 280 & 19.6 & 166 & 11.6 & & $1430(100)$ \\
\hline \multicolumn{9}{|l|}{ Age (years) } \\
\hline $\begin{array}{l}<40 \\
\geqslant 40\end{array}$ & $\begin{array}{c}38 \\
946\end{array}$ & $\begin{array}{c}3.9 \\
96.1\end{array}$ & $\begin{array}{l}25 \\
255\end{array}$ & $\begin{array}{r}8.9 \\
91.1\end{array}$ & $\begin{array}{c}18 \\
148\end{array}$ & $\begin{array}{l}10.8 \\
89.2\end{array}$ & $<0.001$ & $\begin{array}{c}81(5.7) \\
1349(94.3)\end{array}$ \\
\hline \multicolumn{9}{|l|}{ Tumour size (mm) } \\
\hline $\begin{array}{l}\leqslant 20 \\
>20\end{array}$ & $\begin{array}{l}792 \\
192\end{array}$ & $\begin{array}{l}80.5 \\
19.5\end{array}$ & $\begin{array}{c}192 \\
88\end{array}$ & $\begin{array}{l}68.6 \\
31.5\end{array}$ & $\begin{array}{l}94 \\
72\end{array}$ & $\begin{array}{l}56.6 \\
43.4\end{array}$ & $<0.001$ & $\begin{array}{c}1078(75.4) \\
352(24.6)\end{array}$ \\
\hline \multicolumn{9}{|l|}{ Axillary lymph nodes } \\
\hline $\begin{array}{l}\text { Negative } \\
\text { Positive }\end{array}$ & $\begin{array}{l}700 \\
284\end{array}$ & $\begin{array}{l}71.1 \\
28.9\end{array}$ & $\begin{array}{l}159 \\
121\end{array}$ & $\begin{array}{l}56.8 \\
43.1\end{array}$ & $\begin{array}{l}88 \\
78\end{array}$ & $\begin{array}{l}53.0 \\
47.0\end{array}$ & $<0.001$ & $\begin{array}{l}947(66.2) \\
483(33.8)\end{array}$ \\
\hline \multicolumn{9}{|l|}{ Pathological type } \\
\hline $\begin{array}{l}\text { Ductal } \\
\text { Lobular } \\
\text { Other }\end{array}$ & $\begin{array}{c}754 \\
146 \\
84\end{array}$ & $\begin{array}{c}76.6 \\
14.8 \\
8.6\end{array}$ & $\begin{array}{c}238 \\
28 \\
14\end{array}$ & $\begin{array}{c}85.0 \\
10.0 \\
5.0\end{array}$ & $\begin{array}{c}151 \\
11 \\
4\end{array}$ & $\begin{array}{l}91.0 \\
6.6 \\
2.4\end{array}$ & $<0.001$ & $\begin{array}{c}1143(79.9) \\
185(13.0) \\
102(7.1)\end{array}$ \\
\hline \multicolumn{9}{|l|}{ Grade } \\
\hline $\begin{array}{l}1 \\
2 \\
3\end{array}$ & $\begin{array}{c}524 \\
450 \\
10\end{array}$ & $\begin{array}{c}53.3 \\
45.7 \\
1.0\end{array}$ & $\begin{array}{c}52 \\
172 \\
56\end{array}$ & $\begin{array}{l}18.6 \\
61.4 \\
20.0\end{array}$ & $\begin{array}{c}0 \\
53 \\
113\end{array}$ & $\begin{array}{c}0 \\
31.9 \\
68.0\end{array}$ & $<0.001$ & $\begin{array}{l}576(40.3) \\
675(47.2) \\
179(12.5)\end{array}$ \\
\hline \multicolumn{9}{|l|}{ Treatment } \\
\hline None & 267 & 27.1 & 30 & 10.7 & 8 & 4.8 & $<0.001$ & $305(21.3)$ \\
\hline Chemotherapy alone & 9 & 0.9 & 4 & 1.5 & 7 & 4.2 & & $20(1.4)$ \\
\hline Hormone therapy alone & 457 & 46.4 & 114 & 40.7 & 40 & 24.1 & & $611(42.7)$ \\
\hline Both & 251 & 25.6 & 132 & 47.1 & 111 & 66.9 & & $494(34.6)$ \\
\hline
\end{tabular}


In the multivariate analysis, DFS of the discrepant group still was lower than that of the low MI/low Ki67 group: $\mathrm{HR}=2.07,95 \%$ CI 1.31-3.26; $P=0.002$ (Table 2). Regarding BCSS in the multivariate analysis, the same type of results were obtained with a $\mathrm{HR}=3.01,95 \%$ CI $(1.32-6.84 ; P=0.008)$ for the discrepant group compared with the low-proliferative group. The high MI/high Ki67 group also had a greater risk of dying from breast cancer when compared with the low MI/low Ki67 group: $\mathrm{HR}=4.30,95 \%$ CI $(1.63-11.30 ; P=0.003$; data not shown).

As the discrepant group had intermediate BCSS and DFS, we tried to find a discriminatory factor and analysed survival according to the PR status (Prat et al, 2013). In the high MI/high Ki67 and the low MI/low Ki67 groups, the PR level was not relevant regarding BCSS (Supplementary Figure) or DFS. In the discrepant group, patients with $P R \geqslant 20 \%$ tended to have better BCSS (HR $=0.50,95 \%$ CI $(0.15-1.06), P=0.06$; Supplementary Figure) and better DFS (HR $=0.61,95 \%$ CI $(0.31-1.18), P=0.14)$.

As for grade 2 tumours the decision whether or not to administer chemotherapy is still more difficult, we also analysed whether the proliferation groups had an impact on the survival in

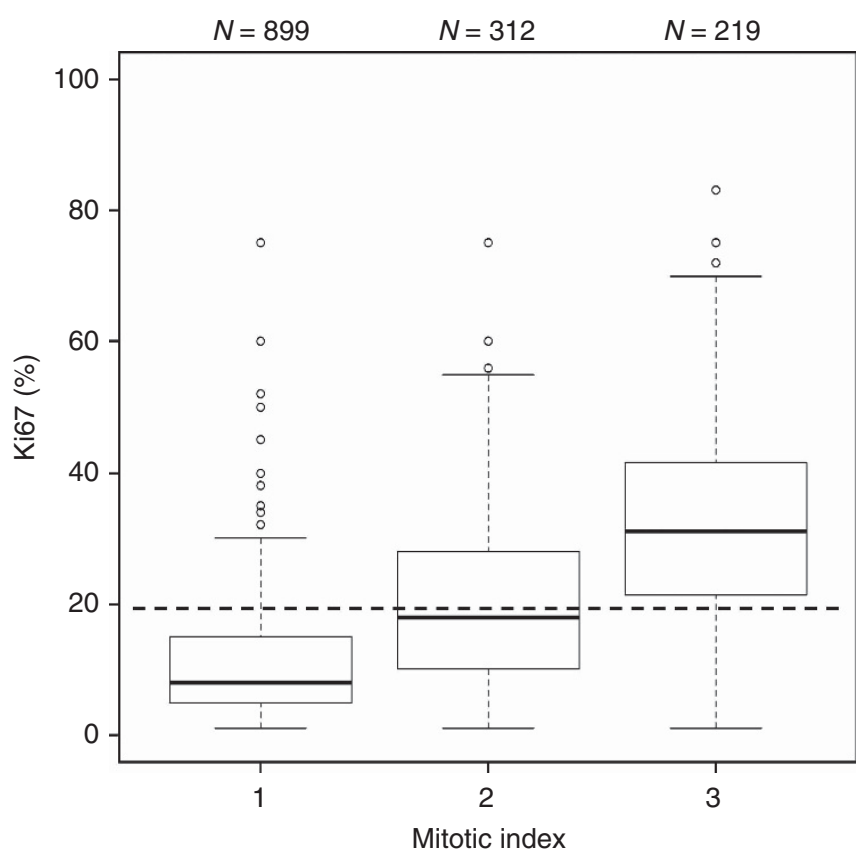

Figure 1. Distribution of Ki67 and mitotic index. The median Ki67 was $8 \%$ in the $\mathrm{Ml}=1$ group, $18 \%$ in the $\mathrm{Ml}=2$ group and $31 \%$ in the $\mathrm{Ml}=3$ group.

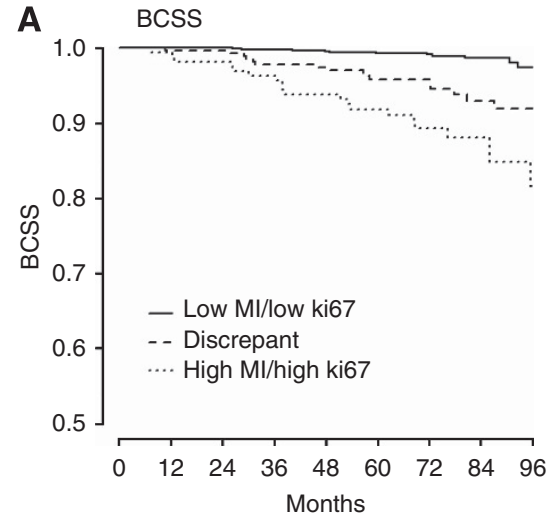

this subgroup. In grade $2 \mathrm{HR}+\mathrm{HER} 2-$ tumour subgroup $(N=675)$, patients with discrepant MI and Ki67 had worse DFS than the low-proliferative group: $\mathrm{HR}=2.18(1.28-3.72 ; P=0.004$; Figure 3). Patients with high MI/high Ki67 had even worse DFS than the low-proliferative group: $H R=3.15(1.57-6.32 ; P=0.001$; Figure 3 ). In the multivariate analysis, DFS of the discrepant and the high MI/high Ki67 group was still significantly lower than that of the low MI/low Ki67 group: $\mathrm{HR}=1.98,95 \%$ CI (1.14-3.46), $P=0.02$ and $\mathrm{HR}=2.97,95 \% \mathrm{CI}(1.42-6.20), P=0.004$, respectively (Supplementary Table). In terms of BCSS, the obtained results were similar. In the multivariate analysis, the discrepant group had a lower BCSS than the low MI/low Ki67 group: $\mathrm{HR}=3.08,95 \% \mathrm{CI}(1.16-8.19), P=0.02$.

\section{DISCUSSION}

Various studies have shown that the cell proliferation markers MI and Ki67 were positively correlated (Spyratos et al, 2002; Offersen et al, 2003; Trihia et al, 2003) and were associated with breast cancer prognosis (De Azambuja et al, 2007; Stuart-Harris et al, 2008; Yerushalmi et al, 2010). However, they differ in some cases. Our study showed that HR + HER2 - tumours with disproportionate MI and Ki67 had higher tumour size, higher grade and more frequent metastatic axillary node involvement than the low Ki67/ low MI group. The discrepant group showed lower tumour size, lower grade and less frequent metastatic axillary lymph nodes than the high Ki67/high MI group. BCSS and DFS of the discrepant group $(\mathrm{HR}=3.01,95 \% \mathrm{CI}(1.32-6.84), P=0.008$ and $\mathrm{HR}=2.07$, $95 \%$ CI (1.31-3.26), $P=0.002$, respectively) were situated between those of the low-proliferative and high-proliferative groups. There was no significant difference regarding the tumour's characteristics within the discrepant group between the high MI/low Ki67 and the low MI/high Ki67 tumours, except for grade.

There is no consensual cutoff value to distinguish low and high Ki67 expression reflecting low or high tumour's proliferative potential. According to the St Gallen guidelines 2013 (Goldhirsch et al, 2013), the threshold to separate luminal A and luminal B cancers is $14 \%$, from one study of gene-expression profiling (Cheang et al, 2009). In terms of prognosis, the threshold of $20 \%$ was suggested in these guidelines, but should be adjusted on local laboratory specificities because of the high degree of variation of Ki67 measurement. We chose the cutoff point of $20 \%$ as it was the threshold set in clinical routine in our institution to discriminate between high- and low-proliferation tumours.

One previous study focused on the prognosis of breast cancer with discrepant MI and Ki67 (Jalava et al, 2006). It included 265 invasive breast cancer cases and split them into four groups on the

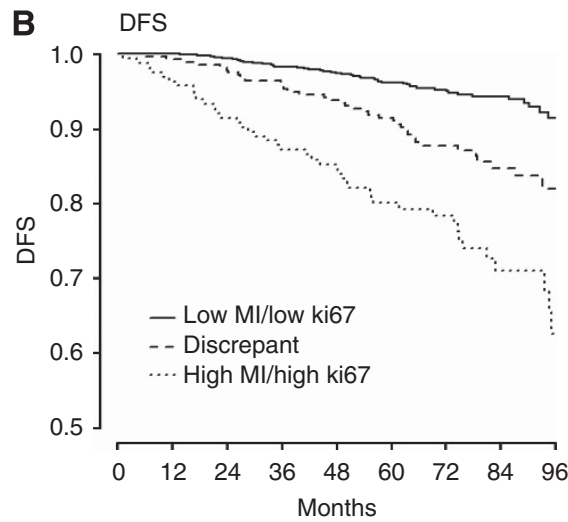

Figure 2. BCSS and DFS according to the proliferation group. BCSS, breast cancer-specific survival; DFS, disease-free survival; HR, hazard ratio; $\mathrm{MI}$, mitotic index. (A) For BCSS, HR discrepant group =4.35 (2.06-9.21; $P=0.0001)$. HR 'high MI/high Ki67' group $=9.77$ (4.80-19.89; $P<0.0001)$. (B) For DFS, HR discrepant group $=2.49$ (1.64-3.76; $P<0.0001)$. HR 'high MI/high Ki67' group $=4.97(3.32-7.43 ; P<0.0001)$. 
Table 2. Prognosis factors on DFS: univariate and multivariate analyses

\begin{tabular}{|c|c|c|c|c|}
\hline Variable /category & Univariate HR $(95 \% \mathrm{Cl})$ & $P$-value & Multivariate HR (95\% Cl) & $P$-value \\
\hline \multicolumn{5}{|l|}{ Age (years) } \\
\hline $\begin{array}{l}<40 \\
\geqslant 40\end{array}$ & $\begin{array}{c}1 \\
0.83(0.42-1.63)\end{array}$ & 0.59 & \multicolumn{2}{|c|}{ NS } \\
\hline \multicolumn{5}{|l|}{ Tumour size $(\mathrm{mm})$} \\
\hline $\begin{array}{l}\leqslant 20 \\
>20\end{array}$ & $\begin{array}{c}1 \\
3.24(2.31-4.55)\end{array}$ & $<0.001$ & $\begin{array}{c}1 \\
2.60(1.82-3.70)\end{array}$ & $<0.001$ \\
\hline \multicolumn{5}{|l|}{ Axillary lymph nodes } \\
\hline $\begin{array}{l}\text { Negative } \\
\text { Positive }\end{array}$ & $\begin{array}{c}1 \\
1.93(1.38-2.71)\end{array}$ & $<0.001$ & $\begin{array}{c}1 \\
1.88(1.23-2.89)\end{array}$ & 0.004 \\
\hline \multicolumn{5}{|l|}{ Pathological type } \\
\hline $\begin{array}{l}\text { Ductal } \\
\text { Lobular } \\
\text { Other }\end{array}$ & $\begin{array}{c}1 \\
0.87(0.51-1.46) \\
0.75(0.35-1.60)\end{array}$ & $\begin{array}{l}0.59 \\
0.45\end{array}$ & \multicolumn{2}{|c|}{ NS } \\
\hline \multicolumn{5}{|l|}{ Grade } \\
\hline $\begin{array}{l}1 \\
2 \\
3\end{array}$ & $\begin{array}{c}1 \\
1.93(1.24-3.01) \\
4.92(3.04-7.95)\end{array}$ & $\begin{array}{r}0.004 \\
<0.001\end{array}$ & \multicolumn{2}{|c|}{ NS } \\
\hline \multicolumn{5}{|l|}{ Proliferation group } \\
\hline $\begin{array}{l}\text { Low Ml/low Ki67 } \\
\text { Discrepant } \\
\text { High Ml/high Ki67 }\end{array}$ & $\begin{array}{c}1 \\
2.49(1.65-3.77) \\
4.98(3.33-7.46)\end{array}$ & $\begin{array}{l}<0.001 \\
<0.001\end{array}$ & $\begin{array}{l}2.07(1.31-3.26) \\
3.52(2.00-6.18)\end{array}$ & $\begin{array}{r}0.002 \\
<0.001\end{array}$ \\
\hline \multicolumn{5}{|l|}{ Treatment } \\
\hline $\begin{array}{l}\text { None } \\
\text { Chemotherapy alone } \\
\text { Hormone therapy alone } \\
\text { Both }\end{array}$ & $\begin{array}{c}1 \\
5.12(1.90-13.79) \\
1.08(0.63-1.88) \\
1.81(1.08-3.06)\end{array}$ & $\begin{array}{l}0.001 \\
0.77 \\
0.02\end{array}$ & $\begin{array}{c}1 \\
1.98(0.69-5.70) \\
0.71(0.40-1.25) \\
0.47(0.24-0.90)\end{array}$ & $\begin{array}{l}0.20 \\
0.23 \\
0.024\end{array}$ \\
\hline
\end{tabular}

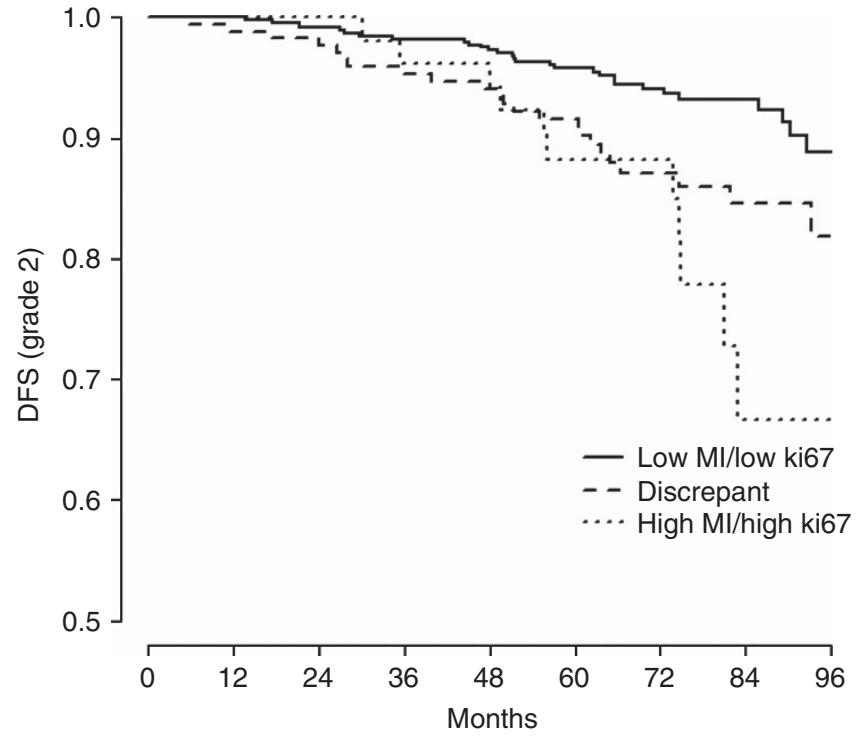

Figure 3. Grade 2 tumours. DFS according to the proliferation group. HR discrepant group $=2.18(1.28-3.72 ; P=0.004)$. HR 'high MI/high Ki67' group $=3.15(1.57-6.32 ; P=0.001)$.

basis of Ki67 (cutoff 15\%) and MI (cutoff 17 mitoses $\mathrm{mm}^{-2}$ ). Patients with high MI/low Ki67 had an OS approaching that of the high MI/high Ki67 group, whereas patients with low MI/high Ki67 had a better prognosis close to that of the low MI/low Ki67 group. Some care is needed while interpreting these data because of the limited number of patients. Hence, we initially analysed our data split into four groups and saw that the two discrepant groups (high MI/low Ki67 and low MI/high Ki67) were not significantly different from each other in terms of tumour characteristics and survival. There was no difference when comparing the BCSS of the low MI/high Ki67 group to the BCSS of the high MI/low Ki67 group: $\mathrm{HR}=0.89(0.25-3.14), P=0.86$ (log-rank test). There was no difference either when regarding DFS of the low MI/high Ki67 compared with that of the high MI/low Ki67 group: $\mathrm{HR}=0.77,95 \%$ CI $(0.35-1.68), P=0.51$. As these two groups looked similar, we decided to analyse them together and to form a larger group of patients.

The median Ki67 in the high MI/low Ki67 group was 15\%. It means that only $50 \%$ of the values of this subgroup were between 15 and $20 \%$, close to the threshold and that a significant part of the values of Ki67 was really low. This median of $15 \%$ was significantly higher than that of the low MI/low Ki67 group (median $=8 \%$ ). In the low MI/high Ki67 subgroup, the median Ki67 was 30\%. This subgroup contained high values of Ki67, distant from the threshold of $20 \%$. This median of $30 \%$ was significantly lower than that of the high MI/high Ki67 group (median $=45.8 \%$ ). Moreover, MI of this subgroup low MI/high Ki67 was measured equal to 1 in $46 \%$ of cases (104 patients) and to 2 in $54.2 \%$ of cases (123 patients).

Low MI/high Ki67 could be explained by the fact that Ki67 protein reflects the proportion of cells in cycle, indicating the cells with propensity to divide. These cells may also stop their cycles or get into apoptosis and not reach mitosis phase. High MI/low Ki67 is harder to explain. MI could be overstated because of mitotic blocks for DNA repair, leading to a larger number of mitotic figures being counted. However, it includes a small number of cells and this hypothesis is insufficient to explain the $3.7 \%$ of high MI/ low Ki67 tumours. Measurement errors of Ki67 cannot be excluded but the semiquantitative method used showed its equivalence to the quantitative one and its intraobserver and extraobserver reproducibility (Caly et al, 2004).

If these explanations were enough, patients with high $\mathrm{MI} / \mathrm{low}$ Ki67 should have a similar prognosis to those with high MI/high $\mathrm{Ki} 67$ because of the underestimation of Ki67, as found by Jalava 
et al (2006). Yet, BCSS and DFS of patients with high MI/low Ki67 tumours were significantly better than those with high $\mathrm{MI} /$ high Ki67 and were comparable to those of low MI/high Ki67 tumours, forming the discrepant group.

Studies are more clear on the prognostic value of MI than on that of Ki67 (Offersen et al, 2003), and the interpretation of the latter is still not standardised. Some studies have shown the prognostic value of Ki67 (De Azambuja et al, 2007; Stuart-Harris et al, 2008) and it has the advantage of identifying the proliferative cells outside a mitotic stage (Vincent-Salomon et al, 2004). However, as suggested by other studies (Spyratos et al, 2002; Gudlaugsson et al, 2013), we demonstrated here that in terms of survival, it is interesting to consider the two markers together and not only independently. This particularly applies to the situations where MI is equal to 2 or when Ki67 is between 10 and $25 \%$, in which the choice to indicate chemotherapy is not unquestionable. These results need to be confirmed in further studies with a longer follow-up, as in $\mathrm{HR}+\mathrm{HER} 2-$ populations breast cancer recurrences might occur later.

It is very interesting to notice that within the HR + HER2 grade 2 tumour subgroup the analysis of MI and Ki67 together could help to precise different prognosis. In terms of DFS (Figure 3, Supplementary Table) and BCSS (data not shown), the discrepant group had lower survival than the low MI/low Ki67 group (DFS HR $=1.98,95 \% \mathrm{CI}(1.14-3.46), P=0.02$ and BCSS $\mathrm{HR}=3.08,95 \% \mathrm{CI}(1.16-8.19), P=0.02)$. It has been shown that Ki67 could help to classify grade 2 tumours into two distinct subgroups (Aleskandarany et al, 2011); however, here we highlight that it should be considered jointly with MI to avoid misclassification towards prognosis.

Progesterone receptor is part of the ER signalling network and has been shown to be a major prognosis stratifier within the luminal breast cancers (Braun et al, 2013; Nishimukai et al, 2014). In our study, the analysis of BCSS (Supplementary Figure) or DFS of HR + HER - patients did not seem to be affected by the PR status (cutoff 20\% (Prat et al, 2013)); however, in the discrepant group patients with $\mathrm{PR} \geqslant 20 \%$ had almost significantly better BCSS (HR $=0.50,95 \%$ CI $(0.15-1.06)$, log-rank $P=0.06)$. Further research will specify the place given to tumour characterisation techniques by multigene microarray (Albain et al, 2010) as well as other complementary prognostic markers such as the expression of Bcl-2 (B-cell lymphoma 2) anti-apoptotic protein (Hwang et al, 2012) and androgen receptor (Vera-Badillo et al, 2014).

Prognosis of HR + HER2 - tumours with inconsistent MI and Ki67 is intermediate between those of high MI/high Ki67 and low MI/low Ki67 tumours, including grade 2 tumours. This study suggests that the combined analysis of KI67 and MI is important in accurately determining the aggressiveness of HR + HER2 - breast cancers.

\section{REFERENCES}

Albain KS, Barlow WE, Shak S, Hortobagyi GN, Livingston RB, Yeh I-T, Ravdin P, Bugarini R, Baehner FL, Davidson NE, Sledge GW, Winer EP, Hudis C, Ingle JN, Perez EA, Pritchard KI, Shepherd L, Gralow JR, Yoshizawa C, Allred DC, Osborne CK, Hayes DF. Breast Cancer Intergroup of North America (2010) Prognostic and predictive value of the 21-gene recurrence score assay in postmenopausal women with nodepositive, oestrogen-receptor-positive breast cancer on chemotherapy: a retrospective analysis of a randomised trial. Lancet Oncol 11: 55-65.

Aleskandarany MA, Rakha EA, Macmillan RD, Powe DG, Ellis IO, Green AR (2011) MIB1/Ki-67 labelling index can classify grade 2 breast cancer into two clinically distinct subgroups. Breast Cancer Res Treat 127: 591-599.

Andre F, Khalil A, Slimane K, Massard C, Mathieu MC, Vignot S, Assi H, Delaloge S, Spielmann M (2005) Mitotic index and benefit of adjuvant anthracycline-based chemotherapy in patients with early breast cancer. J Clin Oncol 23: 2996-3000.
Baak JPA, van Diest PJ, Janssen EAM, Gudlaugsson E, Voorhorst FJ, van der Wall E, Vermorken JB. Collaborators of Multicenter Morphometric Mammary Carcinoma Project (MMMCP) (2008) Proliferation accurately identifies the high-risk patients among small, low-grade, lymph nodenegative invasive breast cancers. Ann Oncol 19: 649-654.

Baak JPA, van Diest PJ, Voorhorst FJ, van der Wall E, Beex LVAM, Vermorken JB, Janssen EAM (2005) Prospective multicenter validation of the independent prognostic value of the mitotic activity index in lymph node-negative breast cancer patients younger than 55 years. J Clin Oncol 23: 5993-6001.

Balaton AL, Coindre JM, Collin F, Ettore F, Fiche M, Jacquemier J, Le Doussal V, Mandard AM, Mathieu MC, Migeon C, Simony-Lafontaine J, Treilleux I, Verriele V, Vilain MO, Zafrani B (1996) Recommendations for the immunohistochemical evaluation of hormone receptors on paraffin sections of breast cancer. Study Group on Hormone Receptors using Immunohistochemistry FNCLCC/AFAQAP. National Federation of Centres to Combat Cancer/French Association for Quality Assurance in Pathology. Ann Pathol 16: 144-148.

Beresford MJ, Wilson GD, Makris A (2006) Measuring proliferation in breast cancer: practicalities and applications. Breast Cancer Res 8: 216.

Braun L, Mietzsch F, Seibold P, Schneeweiss A, Schirmacher P, Chang-Claude J, Peter Sinn H, Aulmann S (2013) sIntrinsic breast cancer subtypes defined by estrogen receptor signalling-prognostic relevance of progesterone receptor loss. Mod Pathol 26: 1161-1171.

Caly M, Genin P, Ghuzlan AA, Elie C, Fréneaux P, Klijanienko J, Rosty C, Sigal-Zafrani B, Vincent-Salomon A, Douggaz A, Zidane M, Sastre-Garau X (2004) Analysis of correlation between mitotic index, MIB1 score and S-phase fraction as proliferation markers in invasive breast carcinoma. Methodological aspects and prognostic value in a series of 257 cases. Anticancer Res 24: 3283-3288.

Cheang MCU, Chia SK, Voduc D, Gao D, Leung S, Snider J, Watson M, Davies S, Bernard PS, Parker JS, Perou CM, Ellis MJ, Nielsen TO (2009) Ki67 index, HER2 status, and prognosis of patients with luminal B breast cancer. J Natl Cancer Inst 101: 736-750.

Clarke RB, Howell A, Potten CS, Anderson E (1997) Dissociation between steroid receptor expression and cell proliferation in the human breast. Cancer Res 57: 4987-4991.

De Azambuja E, Cardoso F, de Castro Jr G, Colozza M, Mano MS, Durbecq V, Sotiriou C, Larsimont D, Piccart-Gebhart MJ, Paesmans M (2007) Ki-67 as prognostic marker in early breast cancer: a meta-analysis of published studies involving 12,155 patients. Br J Cancer 96: 1504-1513.

Dowsett M, Nielsen TO, A’Hern R, Bartlett J, Coombes RC, Cuzick J, Ellis M, Henry NL, Hugh JC, Lively T, McShane L, Paik S, Penault-Llorca F, Prudkin L, Regan M, Salter J, Sotiriou C, Smith IE, Viale G, Zujewski JA, Hayes DF. International Ki-67 in Breast Cancer Working Group (2011) Assessment of Ki67 in breast cancer: recommendations from the International Ki67 in Breast Cancer working group. J Natl Cancer Inst 103: $1656-1664$

Elston CW, Ellis IO (1991) Pathological prognostic factors in breast cancer. I. The value of histological grade in breast cancer: experience from a large study with long-term follow-up. Histopathology 19: 403-410.

Goldhirsch A, Winer EP, Coates AS, Gelber RD, Piccart-Gebhart M, Thürlimann B, Senn H-J. Panel members (2013) Personalizing the treatment of women with early breast cancer: highlights of the St Gallen International Expert Consensus on the Primary Therapy of Early Breast Cancer 2013. Ann Oncol 24: 2206-2223.

Gudlaugsson E, Klos J, Skaland I, Janssen EAM, Smaaland R, Feng W, Shao Z, Malpica A, Baak JPA (2013) Prognostic comparison of the proliferation markers (mitotic activity index, phosphohistone H3, Ki67), steroid receptors, HER2, high molecular weight cytokeratins and classical prognostic factors in $\mathrm{T}_{1-2} \mathrm{~N}_{0} \mathrm{M}_{0}$ breast cancer. Pol J Pathol 64: 1-8.

Harris L, Fritsche H, Mennel R, Norton L, Ravdin P, Taube S, Somerfield MR, Hayes DF, Bast Jr RC. American Society of Clinical Oncology (2007) American Society of Clinical Oncology 2007 update of recommendations for the use of tumor markers in breast cancer. J Clin Oncol 25: 5287-5312.

Hwang K-T, Woo JW, Shin HC, Kim HS, Ahn SK, Moon H-G, Han W, Park IA, Noh D-Y (2012) Prognostic influence of BCL2 expression in breast cancer. Int J Cancer 131: E1109-E1119.

Jalava P, Kuopio T, Juntti-Patinen L, Kotkansalo T, Kronqvist P, Collan Y (2006) Ki67 immunohistochemistry: a valuable marker in prognostication but with a risk of misclassification: proliferation subgroups formed based on Ki67 immunoreactivity and standardized mitotic index. Histopathology 48: 674-682. 
Janssen EAM, van Diest PJ, Søiland H, Gudlaugson E, Nysted A, Voorhorst FJ, Vermorken JB, Søreide J-A, Baak JPA (2006) Success predictors of adjuvant chemotherapy in node-negative breast cancer patients under 55 years. Cell Oncol 28: 295-303.

Lopez F, Belloc F, Lacombe F, Dumain P, Reiffers J, Bernard P, Boisseau MR (1991) Modalities of synthesis of Ki67 antigen during the stimulation of lymphocytes. Cytometry 12: 42-49.

Nishimukai A, Yagi T, Yanai A, Miyagawa Y, Enomoto Y, Murase K, Imamura M, Takatsuka Y, Sakita I, Hatada T, Miyoshi Y (2014) High Ki67 expression and low progesterone receptor expression could independently lead to a worse prognosis for postmenopausal patients with estrogen receptor-positive and HER2-negative breast cancer. Clin Breast Cancer 15: 204-211.

Offersen BV, Sørensen FB, Knoop A, Overgaard J. Danish Breast Cancer Cooperative Tumour Biology Committee (2003) The prognostic relevance of estimates of proliferative activity in early breast cancer. Histopathology 43: $573-582$.

Penault-Llorca F, Abrial C, Raoelfils I, Chollet P, Cayre A, Mouret-Reynier MA, Thivat E, Mishellany F, Gimbergues P, Durando X (2008) Changes and predictive and prognostic value of the mitotic index, Ki-67, cyclin D1, and cyclo-oxygenase- 2 in 710 operable breast cancer patients treated with neoadjuvant chemotherapy. Oncologist 13: 1235-1245.

Penault-Llorca F, Vincent-Salomon A, Bellocq J-P, Matthieu M-C, Grogan GM, Treilleux I, Ettore F, Laberge-Le Couteulx S, Sigal B, Couturier J, Lacroix-Triki M, Antoine M, Balaton A, Baranzelli M-C, Becette V, BlancFournier C, Bibeau F, Brabencova E, Croce S, Fridman V, Génin P, Ghnassia J-P, Jacquemier J, Poulet B, Roger P, Sagan C, Tas P, Trassard M, Verriele V, Arnould L. GEFPICS (2010) [Update of the GEFPICS' recommendations for HER2 status determination in breast cancers in France]. Ann Pathol 30: 357-373.

Prat A, Cheang MCU, Martín M, Parker JS, Carrasco E, Caballero R, Tyldesley S, Gelmon K, Bernard PS, Nielsen TO, Perou CM (2013) Prognostic significance of progesterone receptor-positive tumor cells within immunohistochemically defined luminal A breast cancer. J Clin Oncol 31: 203-209.

Reyal F, Hajage D, Savignoni A, Feron J-G, Bollet MA, Kirova Y, Fourquet A, Pierga J-Y, Cottu P, Dieras V, Fourchotte V, Laki F, Alran S, Asselain B, Vincent-Salomon A, Sigal-Zafrani B, Sastre-Garau X (2013) Long-term prognostic performance of Ki67 rate in early stage, pT1-pT2, pN0, invasive breast carcinoma. PLoS ONE 8: e55901.

Sennerstam R, Auer G (1990) Partition of protein and DNA during cytokinesis in human breast cancer cell lines. Cytometry 11: 292-299.
Spyratos F, Ferrero-Poüs M, Trassard M, Hacène K, Phillips E, Tubiana-Hulin M, Le Doussal V (2002) Correlation between MIB-1 and other proliferation markers: clinical implications of the MIB-1 cutoff value. Cancer 94: 2151-2159.

Stuart-Harris R, Caldas C, Pinder SE, Pharoah P (2008) Proliferation markers and survival in early breast cancer: a systematic review and meta-analysis of 85 studies in 32,825 patients. Breast 17: 323-334.

Trihia H, Murray S, Price K, Gelber RD, Golouh R, Goldhirsch A, Coates AS, Collins J, Castiglione-Gertsch M, Gusterson BA. International Breast Cancer Study Group (2003) Ki-67 expression in breast carcinoma: its association with grading systems, clinical parameters, and other prognostic factors-a surrogate marker? Cancer 97: 1321-1331.

Van Diest PJ, Baak JP, Matze-Cok P, Wisse-Brekelmans EC, van Galen CM, Kurver PH, Bellot SM, Fijnheer J, van Gorp LH, Kwee WS (1992) Reproducibility of mitosis counting in 2,469 breast cancer specimens: results from the Multicenter Morphometric Mammary Carcinoma Project. Hum Pathol 23: 603-607.

Vera-Badillo FE, Templeton AJ, de Gouveia P, Diaz-Padilla I, Bedard PL, AlMubarak M, Seruga B, Tannock IF, Ocana A, Amir E (2014) Androgen receptor expression and outcomes in early breast cancer: a systematic review and meta-analysis. J Natl Cancer Inst 106: djt319.

Viale G, Regan MM, Mastropasqua MG, Maffini F, Maiorano E, Colleoni M, Price KN, Golouh R, Perin T, Brown RW, Kovács A, Pillay K, Ohlschlegel C, Gusterson BA, Castiglione-Gertsch M, Gelber RD, Goldhirsch A, Coates AS. International Breast Cancer Study Group (2008) Predictive value of tumor Ki-67 expression in two randomized trials of adjuvant chemoendocrine therapy for node-negative breast cancer. J Natl Cancer Inst 100: 207-212.

Vincent-Salomon A, Rousseau A, Jouve M, Beuzeboc P, Sigal-Zafrani B, Fréneaux P, Rosty C, Nos C, Campana F, Klijanienko J, Al Ghuzlan A, Sastre-Garau X. Breast Cancer Study Group (2004) Proliferation markers predictive of the pathological response and disease outcome of patients with breast carcinomas treated by anthracycline-based preoperative chemotherapy. Eur J Cancer 40: 1502-1508.

Yerushalmi R, Woods R, Ravdin PM, Hayes MM, Gelmon KA (2010) Ki67 in breast cancer: prognostic and predictive potential. Lancet Oncol 11: 174-183.

This work is published under the standard license to publish agreement. After 12 months the work will become freely available and the license terms will switch to a Creative Commons AttributionNonCommercial-Share Alike 4.0 Unported License.

Supplementary Information accompanies this paper on British Journal of Cancer website (http://www.nature.com/bjc) 